\title{
Planejamento estratégico e gestão por resultados: o caso do Ministério da Saúde
}

\section{| ${ }^{1}$ Luiz Fernando Arantes Paulo |}

Resumo: O objetivo deste trabalho é avaliar em que medida o planejamento estratégico do Ministério da Saúde é aderente a uma estratégia de gestão por resultados, com foco especialmente nas escolhas estratégicas que orientam a organização, ou seja, nos resultados perseguidos. A primeira seção esclarece as premissas metodológicas utilizadas no estudo, que se orientam por três aspectos centrais: 1) as competências legais da administração federal na área da saúde; 2) os conceitos e definições de Gestão por Resultados; e 3) o conceito de resultado para o plano estratégico. Na segunda seção, há uma breve apresentação de como o planejamento estratégico do Ministério é formalizado por meio de três planos estratégicos de forma simultânea (Plano Plurianual, Plano Nacional de Saúde e Plano Estratégico), para em seguida avaliar quão aderente é este planejamento em relação às premissas metodológicas apresentadas na primeira seção. É possível concluir que o planejamento estratégico da União para a área da saúde não observa a divisão de competências definida pelo SUS, estabelecendo objetivos que ultrapassam consideravelmente a esfera de governabilidade do Governo Federal. Esse mesmo planejamento também elege como objetivos medidas administrativas de caráter operacional, que deveriam estar abaixo do recorte existente nos planos estratégicos.

> Palavras-chave: Gestão por Resultados; planejamento estratégico; administração pública; Sistema Único de Saúde.
1 Analista de Planejamento e Orçamento do Governo Federal. Brasília-DF, Brasil (Ifarantespaulo@gmail.com).
Recebido em: 18/08/2015 Aprovado em: 06/01/2016 


\section{Introdução}

Planejar a atuação da administração federal na área da saúde é tarefa complexa. A atuação sobre os problemas de saúde da população é estruturada a partir de um Sistema Único de Saúde (SUS), que tem como uma das diretrizes a descentralização, especialmente para os municípios. Essa descentralização faz com que a maior parte das ações e serviços de saúde oferecidos ao cidadão esteja fora da governabilidade direta do Governo Federal.

Por outro lado, compete ao Ministério da Saúde, em um cenário de queda da participação da União no financiamento da saúde, ${ }^{1}$ garantir padrões de acessibilidade, qualidade e eficiência ao SUS como um todo, respeitando a direção única em cada esfera de governo. A atuação governamental, regida pela legalidade e pelo rigor burocrático dos procedimentos, é cada vez mais pressionada a ampliar sua capacidade de gestão, o que alguns autores identificam como a nova gestão pública (SERRA, 2007, p. 7-8). O desenvolvimento e a apropriação de técnicas, ferramentas e metodologias, antes associadas exclusivamente ao setor privado, servem a um movimento amplo que pressiona o setor público a mais eficiência, eficácia, efetividade e transparência.

É nesse contexto que a estratégia de Gestão por Resultados ${ }^{2}$ ganha relevo na Administração Pública, sendo amplamente difundida a partir do final da década de $1990 .{ }^{3}$ O objetivo deste trabalho é avaliar em que medida o planejamento estratégico do Ministério da Saúde (MS) é aderente a uma estratégia de gestão por resultados, ${ }^{4}$ com foco especialmente nas escolhas estratégicas que orientam a organização, ou seja, nos resultados perseguidos.

Para tanto, o artigo está dividido em duas seções, além desta introdução e das conclusões. A primeira esclarece as premissas metodológicas utilizadas no estudo, que se orientam por três aspectos centrais: 1) as competências legais da administração federal na área da saúde; 2) os conceitos e definiçōes de Gestão por Resultados propostos em estudo de Albert Serra, promovido pelo Banco Interamericano de Desenvolvimento (BID) e pelo Centro Latino-Americano de Administração para o Desenvolvimento (CLAD); e 3) o conceito de resultado para o plano estratégico, conforme utilizado pela Organização das Naçóes Unidas (ONU).

$\mathrm{Na}$ segunda seção, há uma breve apresentação de como o planejamento estratégico do MS é formalizado por meio de três planos estratégicos de forma 
simultânea (Plano Plurianual, Plano Nacional de Saúde e Plano Estratégico) para

em seguida avaliar quão aderente é esse planejamento em relação às premissas metodológicas apresentadas na primeira seção. Para tornar a análise mais direta e transparente, após uma breve análise comparativa entre os três planos, a avaliação sobre as escolhas estratégicas é feita tendo como base o Plano Nacional de Saúde. Essa avaliação consiste em verificar se os objetivos do plano são coerentes com o conceito de resultado considerado no recorte metodológico e com as competências legais da administração federal, bem como avaliar se suas principais atribuições estão destacadas no plano.

É possível concluir que o planejamento estratégico da União para a área da saúde não observa a divisão de competências definida pelo SUS, estabelecendo objetivos que ultrapassam consideravelmente a esfera de governabilidade do Governo Federal. Esse mesmo planejamento também elege como objetivos medidas administrativas de caráter operacional, que deveriam estar abaixo do recorte existente nos planos estratégicos.

\section{Metodologia de avaliação do plano estratégico}

A avaliação do plano estratégico do Ministério da Saúde neste trabalho está restrita à estrutura e às escolhas estratégicas (ou resultados), que são comunicadas como objetivos ou diretrizes, ${ }^{5}$ dependendo do plano considerado. O caminho epistemológico proposto para avaliar o plano estratégico se orienta por três aspectos centrais: 1) as competências legais do Ministério da Saúde; 2) o conceito de resultado para o plano estratégico; 3) as quatro dimensões da estratégia de gestão por resultados propostas por Albert Serra.

Na sequência, estão expostos os parâmetros que instruem a avaliação de cada um dos aspectos citados.

\section{As competências legais do Ministério da Saúde}

A escolha dos resultados a serem perseguidos pela organização, apesar de uma atividade essencialmente política, deve respeitar algumas peculiaridades, especialmente no setor público. Assim, devem ser observadas algumas premissas administrativas que servem como referências para análise da viabilidade do planejamento, dentre as quais se destaca o mapeamento do marco legal e normativo da organização, observando o princípio do Direito Administrativo, de 
que ao agente público só é lícito fazer o que é estabelecido em lei, ao contrário do Direito Civil, em que é lícita toda ação que não é proibida.

É fundamental, portanto, delimitar a competência da organização, a fim de garantir a legalidade de suas iniciativas e a não sobreposição de esforços entre diferentes estruturas da Administração Pública. Em um Estado democrático de direito, as competências legais informam e condicionam todo o processo de gestão, desde as escolhas políticas até a efetiva realização de despesas.

As competências do Ministério da Saúde estão expressamente definidas em duas leis ordinárias, porém com abordagens distintas. Enquanto a Lei no 8.080/90 descreve as ações a serem desempenhadas pela administração federal no âmbito do SUS, a Lei no 10.683/2003, que dispõe sobre a organização da Presidência da República e dos Ministérios, define os assuntos de competência do MS, que englobam e ultrapassam o âmbito do SUS. Na tabela abaixo, está proposta uma correlação entre os dispositivos presentes nas duas leis citadas.

\section{Quadiro 1. Competências do Ministério da Saúde}

\begin{tabular}{|c|c|}
\hline $\begin{array}{l}\text { Lei } \mathrm{n}^{\circ} 10.683 / 2003- \\
\text { Assuntos de competência } \\
\text { do Ministério da Saúde }\end{array}$ & $\begin{array}{l}\text { Lei } n^{\circ} 8.080 / 1990 \text {, art. } 16 \text { - Competências do Ministério da Saúde } \\
\text { no âmbito do SUS }\end{array}$ \\
\hline $\begin{array}{l}\text { a) política nacional de } \\
\text { saúde; }\end{array}$ & $\begin{array}{l}\text { IX - promover articulação com os órgãos educacionais e de fiscalização } \\
\text { do exercício profissional, bem como com entidades representativas de } \\
\text { formação de recursos humanos na área de saúde; } \\
\text { XI - identificar os serviços estaduais e municipais de referência nacional } \\
\text { para o estabelecimento de padrões técnicos de assistência à saúde; } \\
\text { XIII - prestar cooperação técnica e financeira aos Estados, ao Distrito } \\
\text { Federal e aos Municípios para o aperfeiçoamento da sua atuação } \\
\text { institucional; } \\
\text { XIV - elaborar normas para regular as relações entre o Sistema Único } \\
\text { de Saúde (SUS) e os serviços privados contratados de assistência à } \\
\text { saúde; } \\
\text { XV - promover a descentralização para as Unidades Federadas e para } \\
\text { os Municípios, dos serviços e açães de saúde, respectivamente, de } \\
\text { abrangência estadual e municipal; } \\
\text { XVIII - elaborar o Planejamento Estratégico Nacional no âmbito do } \\
\text { SUS, em cooperação técnica com os Estados, Municípios e Distrito } \\
\text { Federal; }\end{array}$ \\
\hline
\end{tabular}

continua... 


\begin{tabular}{|c|c|}
\hline $\begin{array}{l}\text { Lei } \mathrm{n}^{\circ} 10.683 / 2003 \text { - } \\
\text { Assuntos de competência } \\
\text { do Ministério da Saúde }\end{array}$ & $\begin{array}{l}\text { Lei } \text { n }^{\circ} 8.080 / 1990 \text {, art. } 16 \text { - Competências do Ministério da Saúde } \\
\text { no âmbito do SUS }\end{array}$ \\
\hline $\begin{array}{l}\text { b) coordenação e } \\
\text { fiscalização do Sistema } \\
\text { Único de Saúde; }\end{array}$ & $\begin{array}{l}\text { III - definir e coordenar os sistemas: } \\
\text { a) de redes integradas de assistência de alta complexidade; } \\
\text { b) de rede de laboratórios de saúde pública; } \\
\text { c) de vigilância epidemiológica; e } \\
\text { d) vigilância sanitária; } \\
\text { XII - controlar e fiscalizar procedimentos, produtos e substâncias de } \\
\text { interesse para a saúde; } \\
\text { XVI - normatizar e coordenar nacionalmente o Sistema Nacional de } \\
\text { Sangue, Componentes e Derivados; } \\
\text { XVII - acompanhar, controlar e avaliar as açóes e os serviços de saúde, } \\
\text { respeitadas as competências estaduais e municipais; } \\
\text { XIX - estabelecer o Sistema Nacional de Auditoria e coordenar a } \\
\text { avaliação técnica e financeira do SUS em todo o Território Nacional } \\
\text { em cooperação técnica com os Estados, Municípios e Distrito } \\
\text { Federal. (Vide Decreto no } 1.651 \text {, de 1995) }\end{array}$ \\
\hline $\begin{array}{l}\text { c) saúde ambiental e } \\
\text { ações de promoção, } \\
\text { proteção e recuperação } \\
\text { da saúde individual e } \\
\text { coletiva, inclusive a dos } \\
\text { trabalhadores e dos índios; }\end{array}$ & $\begin{array}{l}\text { II - participar na formulação e na implementação das políticas: } \\
\text { a) de controle das agressôes ao meio ambiente; } \\
\text { b) de saneamento básico; e } \\
\text { c) relativas às condições e aos ambientes de trabalho; } \\
\text { IV - participar da definição de normas e mecanismos de controle, com } \\
\text { órgão afins, de agravo sobre o meio ambiente ou dele decorrentes, que } \\
\text { tenham repercussão na saúde humana; } \\
\text { V - participar da definição de normas, critérios e padrões para o } \\
\text { controle das condições e dos ambientes de trabalho e coordenar a } \\
\text { política de saúde do trabalhador; } \\
\text { VI - coordenar e participar na execução das ações de vigilância } \\
\text { epidemiológica; } \\
\text { Parágrafo único. A União poderá executar ações de vigilância } \\
\text { epidemiológica e sanitária em circunstâncias especiais, como na } \\
\text { ocorrência de agravos inusitados à saúde, que possam escapar do } \\
\text { controle da direção estadual do Sistema Único de Saúde (SUS) ou que } \\
\text { representem risco de disseminação nacional. }\end{array}$ \\
\hline d) informaçōes de saúde; & $\begin{array}{l}\text { XI - identificar os serviços estaduais e municipais de referência nacional } \\
\text { para o estabelecimento de padrões técnicos de assistência à saúde; } \\
\text { XVII - acompanhar, controlar e avaliar as ações e os serviços de saúde, } \\
\text { respeitadas as competências estaduais e municipais; }\end{array}$ \\
\hline
\end{tabular}

continua... 


\begin{tabular}{|l|l|}
\hline \multicolumn{1}{|c|}{$\begin{array}{c}\text { Lei no } 10.683 / 2003- \\
\text { Assuntos de competência } \\
\text { do Ministério da Saúde }\end{array}$} & $\begin{array}{l}\text { Lei no 8.080/1990, art. 16 - Competências do Ministério da Saúde } \\
\text { no âmbito do SUS }\end{array}$ \\
\hline $\begin{array}{l}\text { e) insumos críticos para a } \\
\text { saúde; }\end{array}$ & $\begin{array}{l}\text { III - definir e coordenar os sistemas: } \\
\text { b) de rede de laboratórios de saúde pública; } \\
\text { Xolítica nacional e produção de insumos e equipamentos para a saúde, } \\
\text { em articulação com os demais órgãos governamentais; } \\
\text { XVI - normatizar e coordenar nacionalmente o Sistema Nacional de } \\
\text { Sangue, Componentes e Derivados; }\end{array}$ \\
\hline $\begin{array}{l}\text { f) ação preventiva em } \\
\text { geral, vigilância e controle } \\
\text { sanitário de fronteiras e de } \\
\text { portos marítimos, fluviais } \\
\text { e aéreos; }\end{array}$ & $\begin{array}{l}\text { VII - estabelecer normas e executar a vigilância sanitária de portos, } \\
\text { aeroportos e fronteiras, podendo a execução ser complementada pelos } \\
\text { Estados, Distrito Federal e Municípios; }\end{array}$ \\
\hline $\begin{array}{l}\text { g) vigilância de saúde, } \\
\text { especialmente quanto às } \\
\text { drogas, medicamentos e } \\
\text { alimentos; }\end{array}$ & $\begin{array}{l}\text { I - formular, avaliar e apoiar políticas de alimentação e nutrição; } \\
\text { VIII - estabelecer critérios, parâmetros e métodos para o controle da } \\
\text { qualidade sanitária de produtos, substâncias e serviços de consumo e } \\
\text { uso humano; }\end{array}$ \\
\hline $\begin{array}{l}\text { III - definir e coordenar os sistemas: } \\
\text { b) de rede de laboratórios de saúde pública; } \\
\text { tecnologia na área de saúde }\end{array}$ \\
$\begin{array}{l}\text { X formular, avaliar, elaborar normas e participar na execução da } \\
\text { política nacional e produção de insumos e equipamentos para a saúde, } \\
\text { em articulação com os demais órgãos governamentais; }\end{array}$ \\
\hline
\end{tabular}

Fonte: Leis n ${ }^{\circ} 8.080 / 90$ e 10.683/2003. Elaboração do autor.

Apesar de ser possível estabelecer uma correlação entre os dispositivos legais, é certamente um exercício com uma considerável margem de discricionariedade. Não parece, contudo, que haja conflito entre as normas, em que fosse necessário definir a precedência de uma sobre outra. Assim, parte-se da perspectiva de que ambas as leis podem ter vigência ao mesmo tempo, e dessa forma, a observância de uma lei não impede que os dispositivos da outra também sejam respeitados.

Contudo, para compreender com clareza a delimitação do papel do Ministério da Saúde, além da referência legal é necessário examinar como está organizada a divisão de atribuições entre os entes federativos no âmbito da saúde.

\section{A organização do Sistema Único de Saúde 6}

A Constituição Federal de 1988 estabelece, em seu art. 196, que a saúde é direito de todos e dever do Estado, garantido mediante políticas sociais e econômicas. 
Não se trata, portanto, de um compromisso a ser cumprido exclusivamente por serviços de saúde, já que abrange expressamente políticas sociais e econômicas, sob responsabilidade de outros setores.

O dispositivo constitucional tem o sentido claro de reconhecer que a saúde da população pode ser promovida por políticas outras que não as específicas da área da saúde. Como exemplo, é possível associar melhorias em indicadores de saúde a partir de políticas de educação, moradia, meio ambiente, renda ou saneamento, ${ }^{7}$ conforme representado na figura a seguir.

Figura 1. Dever do Estado em relação à saúde

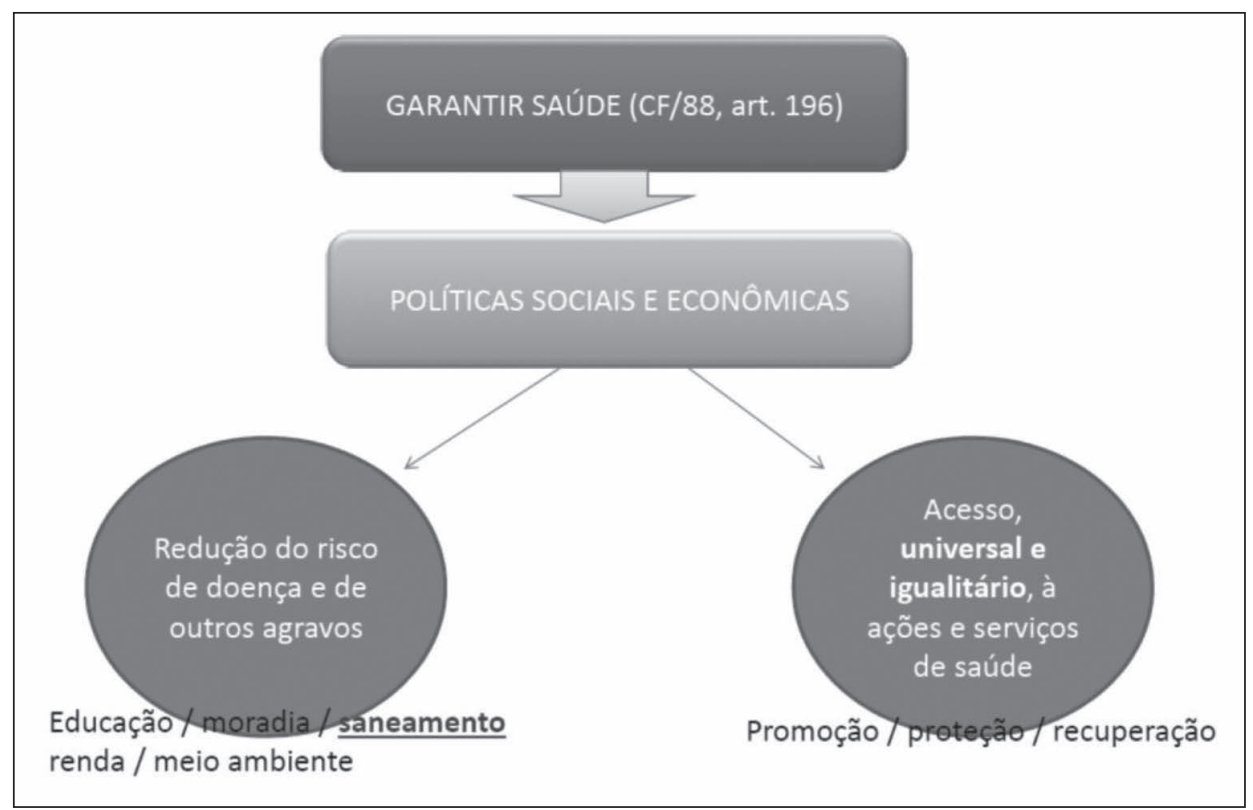

No entanto, a Constituição assegura o acesso universal e igualitário a ações e serviços de saúde, estabelecendo que os serviços são livres à iniciativa privada (art. 199), mas têm relevância pública (art. 197), e que os serviços públicos serão organizados em um sistema único, por meio de uma rede regionalizada e hierarquizada (art. 198). As diretrizes desse sistema único são estabelecidas no art. 198, incisos I a III, a saber: 1) descentralização, com direção única em cada esfera de governo; 2) integralidade; 3) prioridade para a prevenção; 4) participação da comunidade. 


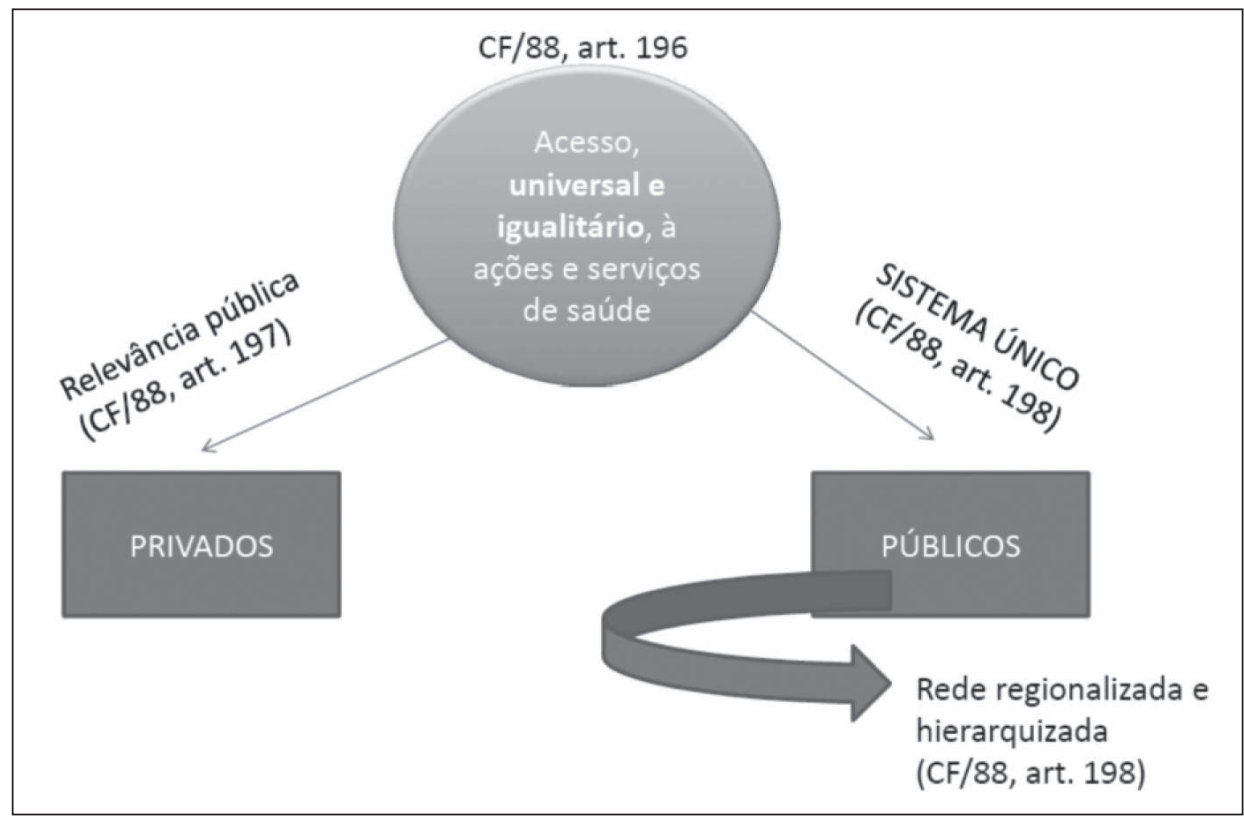

É evidente, pela organização prevista pela Constituição, que a União não responderá diretamente, em regra, pela oferta de açōes e serviços de saúde, dada a diretriz da descentralização, ${ }^{8}$ com direção única em cada esfera de governo. É esta também a orientação que se depreende da Lei de Organização do SUS (Lei no 8.080/90), que define a competência do Ministério da Saúde como responsável pela direção do SUS no âmbito da União. De acordo com o art. 18, inciso I, da Lei no $8.080 / 90$, compete à direção municipal do SUS gerir e executar os serviços públicos de saúde.

A diretriz da descentralização dos serviços é central na organização do SUS. Por outro lado, a Constituição reconhece a maior fragilidade fiscal dos entes municipais e estabelece a corresponsabilização pelo financiamento das ações e serviços de saúde pelos três entes. São previstos recursos mínimos a serem aplicados e estabelecidas regras de rateio, da União para estados e municípios e dos estados para os municípios, objetivando a progressiva redução das disparidades regionais. Assim, a Constituição estabelece como estratégia prioritária do SUS o aprimoramento das ações e serviços oferecidos pelos municípios, contando estes com um financiamento equilibrado e solidário entre os entes. As regras e modelos 
de financiamento do SUS assumem importância fundamental na viabilização da desejada descentralização.

Com relação à União, a Emenda Constitucional no 86, de 2015, define a aplicação mínima de $15 \%$ da receita corrente líquida em ações e serviços de saúde (art. 198, $\$ 2^{\circ}$, inciso I) a partir do quinto ano de sua vigência, estabelecendo uma tabela progressiva para os quatro primeiros anos. ${ }^{9}$ É certo que parte desses recursos será transferida para estados e municípios mediante contrapartida, por força do art. $195, \S 10$, e outra parte será objeto de rateio com os demais entes, com natureza de transferência obrigatória, conforme se depreende do art. 198, $\$$ 3, inciso II e da Lei Complementar no 141 , art. 22, ${ }^{10}$ conforme a figura 3.

Figura 3. Financiamento da descentralização pela Uniāo

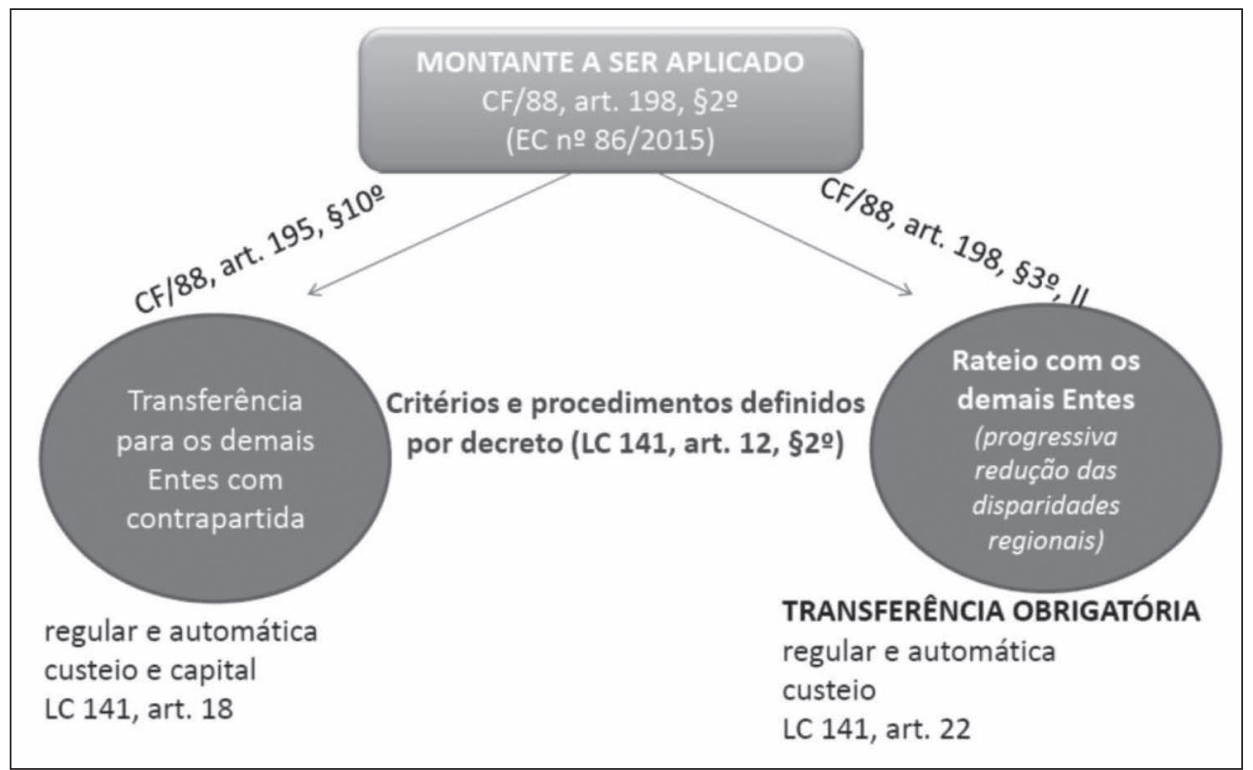

Assim, cabe à União financiar as ações e serviços de saúde a serem prestados por estados e preferencialmente pelos municípios, com o intuito de reduzir as disparidades regionais. O Plano Nacional de Saúde deve indicar o montante de recursos a ser transferido para o financiamento do SUS, conforme regra estabelecida pelo art. $17, \$ 3^{\circ}$ da Lei Complementar $n^{\circ} 141 .{ }^{11}$ Já o ente beneficiário deve ter elaborado seu próprio plano de saúde para receber esses recursos, conforme o art. 22, Súnico, inciso II da mesma lei complementar, e art. 4º, inciso III, da Lei no 8.142/90. 
A transferência dos recursos da União é realizada na modalidade fundo a fundo por meio de blocos de financiamento, conforme disciplinado na Portaria no 204, de 29 de janeiro de 2007, devendo ser observados os critérios estabelecidos no art. 17 da Lei Complementar no 141 e no art. 35 da Lei no 8.080/90, ${ }^{12}$ e ser realizada de forma regular e automática, conforme previsto no art. $3^{\circ}$ da Lei no 8.142/90.

\section{Financiamento dos entes subnacionais pela União}

Entre os anos de 2011 e 2014, cerca de 78\% dos recursos do Fundo Nacional de Saúde foram transferidos para estados, Distrito Federal e municípios, ${ }^{13}$ mas com uma relevante diferença nos valores per capita entre as unidades federativas, conforme aponta o quadro a seguir.

Quadro 2. Valores per capita transferidos na modalidade fundo a fundo

\begin{tabular}{|l|l|l|l|l|l|}
\hline UF & 2011 & 2012 & 2013 & 2014 & $2014 / 2011$ \\
\hline AC & 293,24 & 351,35 & 366,65 & 381,25 & $30,01 \%$ \\
\hline TO & 279,36 & 317,86 & 369,81 & 377,91 & $35,28 \%$ \\
\hline MS & 276,44 & 308,30 & 317,00 & 352,30 & $27,44 \%$ \\
\hline AL & 263,07 & 294,83 & 295,88 & 339,65 & $29,11 \%$ \\
\hline PI & 275,85 & 300,21 & 302,96 & 338,43 & $22,68 \%$ \\
\hline PE & 255,87 & 304,16 & 309,38 & 332,36 & $29,89 \%$ \\
\hline PB & 266,67 & 306,70 & 294,86 & 328,61 & $23,23 \%$ \\
\hline SE & 256,89 & 315,03 & 295,27 & 317,53 & $23,61 \%$ \\
\hline SC & 237,86 & 263,22 & 278,85 & 309,10 & $29,95 \%$ \\
\hline RN & 256,31 & 287,38 & 268,62 & 308,74 & $20,45 \%$ \\
\hline CE & 237,94 & 276,45 & 275,72 & 307,29 & $29,14 \%$ \\
\hline PR & 247,64 & 278,66 & 277,23 & 306,90 & $23,93 \%$ \\
\hline MG & 229,26 & 263,53 & 265,52 & 298,83 & $30,34 \%$ \\
\hline MT & 227,68 & 275,67 & 271,34 & 295,69 & $29,87 \%$ \\
\hline RR & 273,01 & 282,31 & 269,25 & 294,91 & $8,02 \%$ \\
\hline BA & 238,21 & 277,29 & 256,66 & 284,47 & $19,42 \%$ \\
\hline RO & 232,15 & 254,65 & 246,84 & 281,50 & $21,26 \%$ \\
\hline
\end{tabular}




\begin{tabular}{|l|l|l|l|l|l|}
\hline RS & 212,81 & 250,12 & 247,02 & 278,03 & $30,64 \%$ \\
\hline RJ & 217,22 & 239,37 & 244,74 & 274,94 & $26,57 \%$ \\
\hline MA & 224,25 & 254,92 & 266,07 & 274,51 & $22,42 \%$ \\
\hline GO & 221,66 & 241,07 & 246,46 & 273,73 & $23,49 \%$ \\
\hline ES & 220,00 & 244,16 & 245,30 & 271,51 & $23,41 \%$ \\
\hline AP & 216,94 & 263,05 & 279,78 & 270,60 & $24,73 \%$ \\
\hline SP & 223,89 & 244,48 & 238,28 & 266,32 & $18,95 \%$ \\
\hline AM & 212,99 & 228,62 & 220,09 & 237,99 & $11,74 \%$ \\
\hline PA & 185,98 & 212,47 & 216,59 & 231,31 & $24,37 \%$ \\
\hline
\end{tabular}

Fonte: Portal Saúde com Mais Transparência e estimativas populacionais do IBGE.

As células mais escuras destacam as unidades em que houve queda no valor real per capita transferido fundo a fundo entre os anos de 2011 e 2014, considerando uma inflação acumulada de $19,87 \%{ }^{14}$ no período. Em 2014, o Acre recebeu os maiores valores per capita, cerca de $65 \%$ maiores do que os transferidos para o Pará, ${ }^{15}$ unidade que recebeu os menores valores. ${ }^{16}$

Interessa destacar que, dada a magnitude dos valores transferidos em relação ao total dos valores executados pela União e a discrepância no financiamento dos entes, parece desejável que a estratégia de financiamento do SUS seja abordada de forma transparente no plano estratégico do MS, formalizado obrigatoriamente por meio do PPA e do PNS.

Delimitadas e salientadas as competências do Ministério da Saúde, o próximo passo é definir o conceito de resultado.

\section{Sobre o conceito de resultado}

A definição dos resultados a serem perseguidos pela organização é a base do processo de planejamento estratégico (ALDAY, 2000; SILVEIRA; GARCES, 2002; BARBOSA; BRONDANI, 2005; ORTEGON; PACHECO; PRIETO, 2005; CORREA, 2007; SERRA, 2007; UNDG, 2010; PAULO, 2013). Uma escolha equivocada compromete toda a gestão da organização. Para que a alta direção possa debater e definir os resultados, é preciso haver uma harmonização de entendimentos acerca do que pode ser reconhecido como tal. 
É possível encontrar diversas definições para resultado. Neste trabalho, o referencial considerado é o utilizado pela Organização das Nações Unidas (ONU). Para a ONU, resultado é uma alteração mensurável e descritível de um estado de coisas a partir de uma relação de causa e efeito. Assim, resultado pode ser intencional ou não intencional, positivo ou negativo (UNDG, 2010, p. 10). São considerados três tipos de resultados: em relação a programas e projetos, os bens e serviços oferecidos (outputs); em relação ao plano estratégico, ${ }^{17}$ as alteraçōes desejadas na realidade (outcomes) e os efeitos produzidos pela intervenção a longo prazo, diretos ou indiretos, desejados ou não (impacts).

Para avaliar os objetivos destacados no plano estratégico do Ministério da Saúde, ${ }^{18}$ interessa o conceito de "resultado" utilizado para o nível estratégico, que pode ser comunicado de forma simples como "o que se quer", ou outcomes, em distinção ao "o que fazer", ou outputs.

\section{Sobre a estratégia de gestão por resultados}

Existem numerosas abordagens sobre gestão por resultados, que podem ser identificadas por nomes distintos, tais como gestão do desempenho, gestão por objetivos, controle de gestão, entre outros. Este trabalho se baseia nas definiçõos e conceitos propostos por Albert Serra (SERRA, 2007), que destaca quatro dimensões da Gestão por Resultados: 1) resultado como referência-chave para todo o processo de gestão; 2) atribuição de responsabilidades aos resultados pretendidos; 3 ) integração dos processos de gestão; 4) valorização de uma cultura organizacional com ênfase nos resultados, e não nos processos.

Assim, o plano estratégico deve ser capaz de comunicar, de forma clara e simples, quais são os resultados perseguidos pela organização e como eles podem ser mensurados, permitindo o monitoramento e a atribuição de responsabilidade. Esses resultados devem dirigir uma gestão integrada entre plano, orçamento e implementação, moldando a estrutura da organização e seus mecanismos de incentivo (SERRA, 2007).

\section{Da aderência do Planejamento Estratégico da Saúde a uma gestão por resultados}

O planejamento das políticas da administração pública federal para área da saúde deve ser expresso em dois planos: o Plano Nacional de Saúde (PNS) e o 
Plano Plurianual (PPA). Ambos estão previstos na Constituição Federal de 1988.

O PPA está definido expressamente no art. 165 e presente em outros diversos dispositivos. Quanto ao PNS, corresponde ao "plano setorial", previsto de forma genérica no art.48, IV, e referido em outros dispositivos, e expressamente disposto na Lei Complementar no 141 e Lei no 8.080/90. Atualmente, é regulamentado pelo Decreto no 7.508/2011 e Portaria no 2.135/2013. Além do PPA e do PNS, há um terceiro plano, o Plano Estratégico 2011-2015, que expressa uma opção de gestão adotada pelo MS para o período, de caráter gerencial e sob a inteira governabilidade do ministro da Saúde.

A elaboração de três planos estratégicos distintos impõe, na prática, uma dinâmica extremamente complexa de monitoramento e avaliação. O PPA possui uma rotina de monitoramento semestral, formalizado por meio do Sistema Integrado de Planejamento e Orçamento (SIOP), mantido pelo Ministério do Planejamento, Orçamento e Gestão. Para o PNS, há obrigatoriedade de prestação de contas quadrimestralmente, formalizada por meio do Relatório Quadrimestral de Prestação de Contas (RQPC) submetido à apreciação do Conselho Nacional de Saúde. O Plano Estratégico, por sua vez, tem uma dinâmica própria de monitoramento, que pode ser mensal ou em espaços maiores de tempo, de acordo com a prioridade apontada pelo ministro, e conta com um sistema informatizado próprio de acompanhamento, o Ecar.

Diferentes atores identificam diferentes planos como orientação estratégica do ministério. Quando se trata de interfaces com o controle externo, Congresso Nacional ou com a Presidência da República, o plano considerado é o Plano Plurianual. Quando os atores envolvidos são as instâncias representativas e participativas do SUS, como os Conselhos de Saúde e as Comissões Bi e Tripartite, o Plano Nacional de Saúde tem protagonismo. Quando se trata de mobilizar a estrutura interna do ministério, o documento de referência é o Plano Estratégico.

A complexidade descrita não é restrita ao fato de coexistirem três planos estratégicos com dinâmicas distintas de monitoramento e prestação de contas, com diferentes interfaces a depender dos atores interessados. Metodologicamente, os planos foram construídos em bases diferentes, cada um possui uma estrutura própria, com atributos e conteúdos distintos.

Não bastasse todo este contexto a dificultar uma coordenação eficiente da gestão dos planos, nota-se ainda uma confusão semântica e conceitual entre 
eles - ou seja, um mesmo nome pode ser utilizado para designar atributos diferentes em cada plano.

Interessa destacar, ainda, que abaixo dos objetivos/diretrizes, a estratégia dos planos é definida de forma distinta, ou seja, as metas presentes no PNS não são necessariamente as metas presentes no PPA. No mesmo sentido, os resultados do Plano Estratégico podem ser distintos das metas do PNS e PPA, quantitativa ou qualitativamente, além de contar com outros atributos mais operacionais, como marcos intermediários e ações.

A figura 4 e o quadro 3, a seguir, apresentam uma comparação entre a estrutura, os atributos e os conceitos existentes em cada um dos planos. As células com a mesma coloração indicam os atributos que desempenham a mesma função na programação, embora possam ter conceitos distintos, como por exemplo, os resultados descritos no Plano Estratégico, que muitas vezes coincidem com metas do PPA e do PNS.

Figura 4. Instrumentos de planejamento estratégico no MS

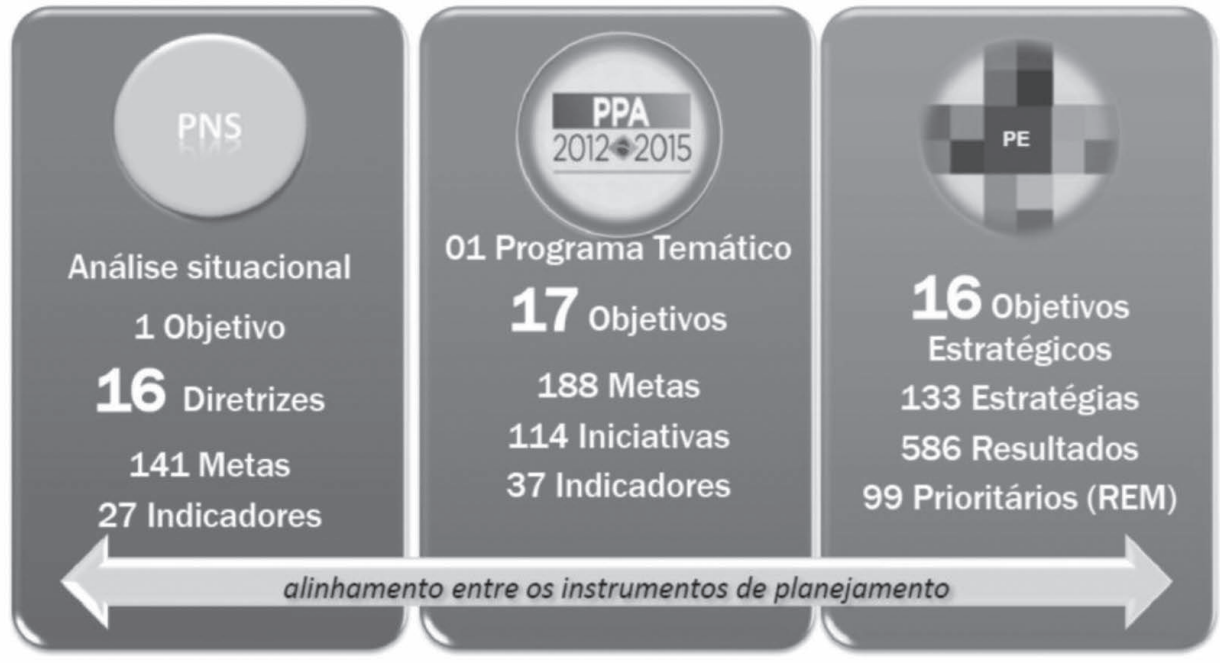

Fonte: Planejamento Estratégico do Ministério da Saúde 2011-2015: resultados e perspectivas. Demas/SE/MS. 


\begin{tabular}{|c|c|c|c|c|c|}
\hline \multicolumn{2}{|c|}{ PLANO PLURIANUAL } & \multicolumn{2}{|c|}{ PLANO NACIONAL DE SAÚDE } & \multicolumn{2}{|c|}{ PLANO ESTRATÉGICO } \\
\hline ATRIBUTO & CONCEITO & ATRIBUTO & CONCEITO & ATRIBUTO & CONCEITO \\
\hline Programa & $\begin{array}{l}\text { Expressa e orienta a } \\
\text { ação governamental } \\
\text { para a entrega de } \\
\text { bens e serviços à } \\
\text { sociedade }\end{array}$ & Objetivos & $\begin{array}{l}\text { Expressam o } \\
\text { que se pretende } \\
\text { fazer acontecer a } \\
\text { fim de superar, } \\
\text { reduzir, eliminar } \\
\text { ou controlar } \\
\text { os problemas } \\
\text { identificados. }\end{array}$ & & \\
\hline Indicador & $\begin{array}{l}\text { É uma referência } \\
\text { que permite } \\
\text { identificar e aferir, } \\
\text { periodicamente, } \\
\text { aspectos } \\
\text { relacionados a } \\
\text { um Programa, } \\
\text { auxiliando o seu } \\
\text { monitoramento e } \\
\text { avaliação. }\end{array}$ & Indicador & $\begin{array}{l}\text { É um índice que } \\
\text { reflete uma situação } \\
\text { determinada, a } \\
\text { partir da relação } \\
\text { entre variáveis, } \\
\text { que permite } \\
\text { medir mudanças e } \\
\text { determinar o grau } \\
\text { de cumprimento de } \\
\text { metas. }\end{array}$ & & \\
\hline Objetivo & $\begin{array}{l}\text { Expressa o que deve } \\
\text { ser feito, reflete as } \\
\text { situações a serem } \\
\text { alteradas pela } \\
\text { implementação de } \\
\text { um conjunto de } \\
\text { Iniciativas. }\end{array}$ & Diretrizes & $\begin{array}{l}\text { Formulações que } \\
\text { indicam as linhas } \\
\text { de ação a serem } \\
\text { seguidas. São } \\
\text { expressas de forma } \\
\text { objetiva - sob } \\
\text { a forma de um } \\
\text { enunciado-síntese - } \\
\text { e visam delimitar a } \\
\text { estratégia geral e as } \\
\text { prioridades do Plano } \\
\text { de Saúde. }\end{array}$ & $\begin{array}{l}\text { Objetivos } \\
\text { Estratégicos }\end{array}$ & $\begin{array}{l}\text { Descrevem os } \\
\text { grandes alvos que } \\
\text { o Ministério da } \\
\text { Saúde busca atingir } \\
\text { em } 2015 \text {. Estão } \\
\text { vinculados ao Plano } \\
\text { Plurianual e ao } \\
\text { Plano Nacional de } \\
\text { Saúde. }\end{array}$ \\
\hline & & & & Estratégias & $\begin{array}{l}\text { São os principais } \\
\text { caminhos, } \\
\text { trajetórias } \\
\text { percorridas para } \\
\text { atingir os Objetivos } \\
\text { Estratégicos e se } \\
\text { constituem como } \\
\text { estratégias da gestão } \\
\text { até } 2015 \text {. }\end{array}$ \\
\hline
\end{tabular}

continua.. 


\begin{tabular}{|c|c|c|c|c|c|}
\hline Metas & $\begin{array}{l}\text { Medida do alcance } \\
\text { do Objetivo, } \\
\text { podendo ser } \\
\text { de natureza } \\
\text { quantitativa ou } \\
\text { qualitativa. }\end{array}$ & Metas & $\begin{array}{l}\text { Expressões } \\
\text { quantitativas de } \\
\text { um objetivo. As } \\
\text { metas concretizam } \\
\text { o objetivo no } \\
\text { tempo e esclarecem } \\
\text { e quantificam "o } \\
\text { que", "pra quem" e } \\
\text { "quando". }\end{array}$ & Resultados & \begin{tabular}{|l} 
Expressam a \\
transformação na \\
realidade almejada \\
pelo grupo que \\
planeja, ao final de \\
determinado prazo. \\
Ou seja, descrevem \\
aquilo que o MS \\
espera atingir em \\
dezembro do ano \\
corrente, fruto da \\
sua ação direta ou \\
indireta. Devem ser \\
claros e verificáveis \\
por qualquer pessoa.
\end{tabular} \\
\hline Iniciativa & $\begin{array}{l}\text { Atributo que declara } \\
\text { as entregas de bens e } \\
\text { serviços à sociedade, } \\
\text { resultantes da } \\
\text { coordenação } \\
\text { de açōes } \\
\text { governamentais, } \\
\text { decorrentes ou não } \\
\text { do orçamento. }\end{array}$ & & & $\begin{array}{l} \\
\text { Marcos } \\
\text { Intermediários } \\
\text { /Produtos }\end{array}$ & $\begin{array}{l}\text { Os produtos, } \\
\text { ou marcos } \\
\text { intermediários, } \\
\text { são entregas } \\
\text { intermediárias } \\
\text { que precisam ser } \\
\text { realizadas para } \\
\text { que o resultado } \\
\text { seja atingido. } \\
\text { Nesse sentido, } \\
\text { configuram-se } \\
\text { como meios para } \\
\text { que o resultado se } \\
\text { concretize. }\end{array}$ \\
\hline & & & & Ações & $\begin{array}{l}\text { São as atividades, } \\
\text { ações necessárias } \\
\text { para a realização } \\
\text { do produto/marco } \\
\text { intermediário }\end{array}$ \\
\hline
\end{tabular}

Fontes: Lei no 12.593 , de 18 de janeiro 2012 (PPA 2012-2015). Sistema de Planejamento do SUS: uma construção coletiva: instrumentos básicos / MS/SE/SPO. - 2.ed. - Brasília: Ministério da Saúde, 2009 p. 26-28. e-car/DEMAS. 
A existência de três planos estratégicos dentro de uma mesma organização, com estruturas, conceitos e semânticas distintas, prejudica de forma decisiva a coordenação de esforços. ${ }^{19}$ Considerando apenas os objetivos, que no PNS são comunicados como "diretrizes", é possível afirmar que PNS e Plano Estratégico são integralmente correspondentes. Com relação ao PPA, há diferenças pontuais, restritas a três objetivos. Assim, há uma clara compatibilidade da orientação estratégica entre os planos. Esse seria um dado positivo se as próprias escolhas estratégicas não fossem, por si só, merecedoras de críticas, uma vez que as diretrizes ou objetivos atualmente declarados revelam pouca aderência ao papel a ser desempenhado pelo Ministério da Saúde.

É preciso destacar que o modelo de planejamento adotado por PPA e PNS não estabelece indicadores ligados aos resultados (objetivos/diretrizes), o que prejudica uma eventual avaliação sobre efetividade do plano. ${ }^{20}$

Para análise qualitativa das escolhas estratégicas do Ministério da Saúde, este trabalho se baseia nas diretrizes definidas no Plano Nacional de Saúde para o período 2012-2015. A escolha se justifica porque o PNS é de inteira governabilidade do MS, enquanto o PPA é coordenado pelo Ministério do Planejamento, Orçamento e Gestão. Com relação ao Plano Estratégico, a escolha pelo PNS se dá por sua previsão normativa e maior formalização, considerando ainda que as escolhas estratégicas são praticamente idênticas entre os dois instrumentos.

O quadro a seguir expõe uma análise crítica das 16 diretrizes do PNS 20122015, considerando os parâmetros metodológicos definidos para este trabalho. 


\begin{tabular}{|l|}
\hline \multicolumn{1}{|c|}{ PNS 2012-2015 } \\
\hline \\
Diretriz 1 - Garantia do acesso da \\
população a serviços de qualidade, \\
com equidade e em tempo adequado \\
ao atendimento das necessidades \\
de saúde, mediante aprimoramento \\
da política de atenção básica e da \\
atenção especializada.
\end{tabular}

Diretriz 2 - Aprimoramento da Rede de Atenção às Urgências, com expansão e adequação de Unidades de Pronto Atendimento (UPA), de Serviços de Atendimento Móvel de Urgência (SAMU), de prontossocorros e centrais de regulação, articulada às outras redes de atenção.

Diretriz 3 - Promoção da atenção integral à saúde $\mathrm{da}$ mulher $\mathrm{e}$ da criança e implementação da "Rede Cegonha", com ênfase nas áreas e populações de maior vulnerabilidade.

Diretriz 4 - Fortalecimento da rede de saúde mental, com ênfase no enfrentamento da dependência de crack e outras drogas.

Diretriz 5 - Garantia da atenção integral à saúde da pessoa idosa e dos portadores de doenças crônicas, com estímulo ao envelhecimento ativo e fortalecimento das ações de promoção e prevenção.

\section{OBSERVAÇÕES}

A União não é capaz de garantir o acesso, uma vez que o SUS privilegia a municipalização dos serviços; Aprimoramento da política é uma expressão com alto grau de indefinição;

Não foram estabelecidos indicadores para verificar o acesso (índice de cobertura não é capaz de aferir acesso a serviços com qualidade, equidade e tempestividade).

A diretriz supera consideravelmente o que pode ser atribuído à competência do Ministério da Saúde e não oferece indicadores capazes de acompanhar os resultados desejados. Há ainda uma confusão acerca dos resultados desejados, se a garantia do acesso ou o aprimoramento da política (caso em que a garantia do acesso poderia ser entendida como impacto, ou resultado mediato).

A rigor, a diretriz 2 é uma subdivisão da diretriz 1, relativa à garantia do acesso à rede de urgência e emergência. A expansão das UPAs e SAMU revelam mais "o que fazer", e não "o que se quer"

A rigor, a diretriz 3 é uma subdivisão da diretriz 1, relativa à garantia do acesso à mulher e criança. Implementar a "Rede Cegonha" carrega uma considerável imprecisão e revelaria, em todo caso, "o que fazer" e não "o que se quer"

A rigor, a diretriz 4 é uma subdivisão da diretriz 1, relativa à garantia do acesso a serviços referentes à dependência química. Fortalecer a rede de saúde carrega uma considerável imprecisão e revelaria "O que fazer" e não "o que se quer"

A rigor, a diretriz 5 é uma subdivisão da diretriz 1, relativa à garantia do acesso a serviços por idosos e portadores de doenças crônicas. O estímulo ao envelhecimento ativo carrega uma considerável imprecisão e revelaria "o que fazer", e não "o que se quer" 


\begin{tabular}{|c|c|}
\hline $\begin{array}{l}\text { Diretriz } 6 \text { - Implementação do } \\
\text { subsistema de atenção à saúde } \\
\text { indígena, articulado com o SUS, } \\
\text { baseado no cuidado integral, com } \\
\text { observância às práticas de saúde } \\
\text { e às medicinas tradicionais, com } \\
\text { controle social, e garantia do respeito } \\
\text { às especificidades culturais. }\end{array}$ & $\begin{array}{l}\text { A rigor, a diretriz } 6 \text { é uma subdivisão da diretriz } 1 \text {, relativa } \\
\text { à garantia de acesso aos povos indígenas. Implementação } \\
\text { do subsistema carrega uma considerável imprecisão e } \\
\text { corresponde a "o que fazer", e não "ao que se quer" }\end{array}$ \\
\hline $\begin{array}{l}\text { Diretriz } 7 \text { - Redução dos riscos } \\
\text { e agravos à saúde da população, } \\
\text { por meio das açōes de promoção e } \\
\text { vigilância em saúde. }\end{array}$ & Sem c \\
\hline $\begin{array}{l}\text { Diretriz } 8 \text { - Garantia da assistência } \\
\text { farmacêutica no âmbito do SUS. }\end{array}$ & $\begin{array}{l}\text { Garantir o acesso a medicamentos parece comunicar } \\
\text { melhor "o que se quer". } \\
\text { A União não é capaz de garantir a integralidade da } \\
\text { assistência farmacêutica, uma vez que o SUS privilegia a } \\
\text { municipalização dos serviços. } \\
\text { A diretriz supera consideravelmente o que pode ser } \\
\text { atribuído à competência do Ministério da Saúde e não } \\
\text { oferece indicadores capazes de acompanhar os resultados } \\
\text { desejados (índice de cobertura da farmácia popular não é } \\
\text { capaz de aferir acesso a medicamentos). }\end{array}$ \\
\hline $\begin{array}{l}\text { Diretriz } 9 \text { - Aprimoramento da } \\
\text { regulação e da fiscalização da saúde } \\
\text { suplementar, com articulaçáo da } \\
\text { relação público-privado, geraçãa de } \\
\text { maior racionalidade e qualidade no } \\
\text { setor saúde. }\end{array}$ & $\begin{array}{l}\text { Aprimorar a regulação e a fiscalização é meio, e não fim, } \\
\text { e dificilmente pode ser acompanhado por indicadores. } \\
\text { Induzir a qualificação dos serviços privados de saúde } \\
\text { parece comunicar melhor "o que se quer". }\end{array}$ \\
\hline $\begin{array}{l}\text { Diretriz } 10 \text { - Fortalecimento do } \\
\text { complexo produtivo e de ciência, } \\
\text { tecnologia e inovação em saúde } \\
\text { como vetor estruturante da agenda } \\
\text { nacional de desenvolvimento } \\
\text { econômico, social e sustentável, } \\
\text { com redução da vulnerabilidade do } \\
\text { acesso à saúde. }\end{array}$ & $\begin{array}{l}\text { Complexo produtivo e CT\&I revelam expectativas } \\
\text { de resultados diferentes. No complexo produtivo, há } \\
\text { expectativa de ganhos de produtividade induzidos pelo } \\
\text { poder de compra governamental. No caso de CT\&I, } \\
\text { aposta-se na pesquisa para gerar descobertas e novos } \\
\text { medicamentos e tratamentos. A reunião sob uma mesma } \\
\text { diretriz pode prejudicar a mobilização dos esforços e a } \\
\text { avaliação dos resultados. }\end{array}$ \\
\hline $\begin{array}{l}\text { Diretriz } 11-\text { Contribuição à } \\
\text { adequada formação, alocação, } \\
\text { qualificação, valorização e } \\
\text { democratização das relações de } \\
\text { trabalho dos trabalhadores do SUS. }\end{array}$ & $\begin{array}{l}\text { A boa formação e alocação de profissionais constitui um } \\
\text { meio para prestação dos serviços de saúde, e não "o que se } \\
\text { quer" de uma política de saúde. }\end{array}$ \\
\hline
\end{tabular}

continua... 
Diretriz 12 - Implementação de novo modelo de gestão e instrumentos de relação federativa, com centralidade na garantia do acesso, gestão participativa com foco em resultados, participação social e financiamento estável.

Diretriz 13 - Qualificação de instrumentos de execução direta, com geração de ganhos de produtividade e eficiência para o SUS.

Diretriz 14-Promoção internacional dos interesses brasileiros no campo da saúde, bem como compartilhamento das experiências e saberes do SUS com outros países, em conformidade com as diretrizes da Política Externa Brasileira.

a) Implementar ações de saneamento básico e saúde ambiental, de forma sustentável, para a promoção da saúde e redução das desigualdades sociais, com ênfase no Programa de Aceleração do Crescimento.

b) Contribuir para erradicar a extrema pobreza no País.
Modelo de gestão e instrumentos de relação federativa constituem meios para a prestação dos serviços de saúde, e não "o que se quer" de uma política de saúde.

Qualificar instrumentos de execução direta é uma típica atividade meio, que pode estar relacionada a qualquer resultado desejado.

Interesses brasileiros no campo da saúde é uma expressão com considerável imprecisão e não comunica "o que se quer". O compartilhamento de experiências é uma típica atividade meio.

Ações de saneamento comunicam "o que fazer", e não "o que se quer”. O resultado pretendido, a rigor, está contido na diretriz 7.

Não é possível identificar correlação entre política de saúde e erradicação da extrema pobreza, que é mensurada por parâmetros exclusivamente econômicos. Pelo contrário, é possível que a redução da extrema pobreza produza consequências positivas nos indicadores de saúde.

Fonte: elaboração própria.

Da análise das 16 Diretrizes do PNS 2012-2015, que desempenham o papel mais próximo da definição de resultado ${ }^{21}$, é possível verificar que:

algumas diretrizes ignoram a regra constitucional de descentralização das açôes e serviços de saúde, associando resultados que ultrapassam a governabilidade do Ministério da Saúde (diretrizes 1, 8 e "b");

- algumas diretrizes não correspondem à definição de resultados perseguidos, mas de estratégias escolhidas ou esforços operacionais associados (diretrizes 9, 11 a 14 e "a"); 
- algumas diretrizes possuem recortes de gestão pouco precisos, sendo possível identificar sobreposições e, portanto, dificuldade em atribuir responsabilização (diretrizes 2 a 6 em relação à diretriz 1).

De uma maneira geral, é possível notar que as competências do Ministério da Saúde definidas nas Leis $n^{\circ}$ s 8.080/90 e 10.683/2003 não serviram como orientadoras do planejamento estratégico. No mesmo sentido, é possível afirmar que o planejamento vigente não é aderente à estratégia de gestão por resultados, uma vez que:

- não há clareza ou harmonia conceitual na definição dos resultados;

- não há responsabilização clara pela obtenção dos resultados definidos;

- o processo de gestão é obstaculizado pela necessidade de articulação entre três planos estratégicos;

- a estrutura organizacional parece condicionar as escolhas estratégicas, e não o contrário, em que a estrutura da organização se molda para a realização do planejamento estratégico.

Além dos comentários referentes às escolhas efetivamente declaradas, há omissões importantes a serem destacadas, dados os desafios da administração federal na gestão da política de saúde.

- não há uma abordagem sobre a estratégia de financiamento dos entes federativos, em cumprimento à diretriz da descentralização das ações e serviços de saúde;

- não há clareza sobre as ações e serviços de saúde sob responsabilidade direta do Ministério da Saúde, bem como sobre as competências relativas à coordenação e fiscalização do SUS.

\section{Conclusões}

O planejamento estratégico do Ministério da Saúde, formalizado atualmente por meio de três planos estratégicos, é pouco aderente a uma estratégia de gestão por resultados. Isso porque os objetivos estratégicos escolhidos para os planos, em sua grande maioria, ou ultrapassam consideravelmente as competências da atuação da esfera federal, ou apenas declaram medidas operacionais adotadas pela administração. Dessa forma, o plano estratégico se torna incapaz de orientar 
e mobilizar a organização, ocupando papel de menor relevância na mobilização da alta direção, sobretudo em razão das seguintes fragilidades:

1) há pouca clareza conceitual sobre o que são "resultados", sendo que o Plano Estratégico mistura em um mesmo nível desde impactos que ultrapassam a governabilidade da administração federal até medidas administrativas e operacionais;

2) não há uma clara correlação entre as escolhas estratégicas declaradas com as competências legais do Ministério da Saúde;

3) ausência de uma abordagem mais clara e direta sobre o papel de financiamento do sistema de saúde;

4) a metodologia atual não estabelece indicadores para os objetivos, o que prejudica sua caracterização e monitoramento e favorece uma gestão majoritariamente voltada para processos, e não resultados;

5) não há atribuição clara de responsabilidade aos objetivos perseguidos, estando diluída na figura institucional do Ministério;

6) a coexistência de três planos estratégicos impõe fragmentação e complexidade exageradas nas rotinas de gestão.

\section{Referências}

ALDAY, H.; CONTRERAS, E. O planejamento estratégico dentro do conceito de administração estratégica. Revista FAE, v. 3, n. 2, Curitiba, p. 9-16, maio-ago. 2000.

ARRETCHE, M. Mitos da descentralização: mais democracia e eficiência nas políticas públicas? Revista Brasileira de Ciências Sociais, n. 31, p. 44-66, 1996.

BARBOSA, E. R.; BRONDANI, G. Planejamento Estratégico Organizacional. Revista Eletrônica de Contabilidade, v. I, n. 2, dez/2004-fev/2005.

BESTER, A. Results-based management in the United Nations Development System: progress and challenges. A report prepared for the United Nations Department of Economic and Social Affairs, for the Quadrennial Comprehensive Policy Review, jul. 2012.

BRASIL. Constituição da República Federativa do Brasil de 1988. Disponível em: <http:// www.planalto.gov.br/ccivil_03/constituicao/constituicaocompilado.htm>. Acesso em: 7 abr. 2015.

Lei Complementar no 141, de 13 de janeiro de 2012 (valores mínimos e critérios de rateio das transferências para a saúde). Disponível em: <http://www.planalto.gov.br/ ccivil_03/leis/LCP/Lcp141.htm>. Acesso em: 7 abr. 2015. 
Lei no 10.683, de 28 de maio de 2003 (organização da Presidência da República

e Ministérios). Disponível em: <http://www.planalto.gov.br/ccivil_03/leis/2003/110.683. htm>. Acesso em 7 abr. 2015.

. Lei no 12.593, de 18 de janeiro de 2012 (PPA 2012-2015). Disponível em: <http://www.planalto.gov.br/ccivil_03/_ato2011-2014/2012/Lei/L12593.htm>. Acesso em 7 abr. 2015.

Lei no 8.080, de 19 de setembro de 1990 (organização dos serviços de saúde). Disponível em: <http://www.planalto.gov.br/ccivil_03/leis/L8080.htm>. Acesso em 7 abr. 2015.

. Lei no 8.142, de 28 de dezembro de 1990 (participação social e transferência de recursos financeiros). Disponível em: <http://www.planalto.gov.br/ccivil_03/leis/L8142. htm>. Acesso em 7 abr. 2015.

- Ministério da Saúde. Portal Saúde com Mais Transparência. Disponível em: <http://aplicacao.saude.gov.br/portaltransparencia/index.jsf>. Acesso em: 30 mar. 2015.

. Secretaria-Executiva. Departamento de Monitoramento e Avaliação do SUS. Planejamento Estratégico do Ministério da Saúde 2011-2015: resultados e perspectivas. Brasília: MS, 2015.

- Portaria no 204, de 29 de janeiro de 2007 (Blocos de Financiamento). Disponível em: <http://bvsms.saude.gov.br/bvs/saudelegis/gm/2007/ prt0204_29_01_2007_comp.html>. Acesso em 7 abr. 2015.

. Portaria no 2.135, de 25 de setembro de 2013 (Diretrizes para o processo de planejamento no SUS). Disponível em: http://bvsms.saude.gov.br/bvs/saudelegis/ gm/2013/prt2135_25_09_2013.html. Acesso em 7 abr. 2015.

- Secretaria-Executiva. Subsecretaria de Planejamento e Orçamento.

Sistema de Planejamento do SUS: uma construção coletiva: instrumentos básicos. 2.ed. Brasília: MS, 2009.

Ministério do Planejamento, Orçamento e Gestão. Instituto Brasileiro de Geografia e Estatística. Estimativas populacionais para os municípios brasileiros. Disponível em: <http://www.ibge.gov.br/home/estatistica/populacao/estimativa2014/estimativa_dou. shtm>. Acesso em: 30 mar. 2015.

CARVALHO, G. A inconstitucional administração pós-constitucional do SUS através de normas operacionais. Revista Ciência \& Saúde Coletiva, v. 6, no 2, p. 435-444, 2001

CARVAlHO, G.; SANTOS, N. R. dos. Desafios de se cumprir as leis da saúde. Blog Saúde Brasil, 2013. Disponível em: <http://apsp.org/?p=2885>. Acesso em: $22 \mathrm{dez} .2015$.

CHIAVENATO, I. Administração geral e pública. Rio de Janeiro: Elsevier, 2006. 
CORRÊA, I. M. Planejamento estratégico e gestão pública por resultados no processo de reforma administrativa do estado de Minas Gerais. Revista de Administraçao Pública. Rio de Janeiro, v. 41, no 3 p. 487-504, maio/jun. 2007.

DRUCKER, P. Managing for results: economic tasks and risk-taking decisions. New York, Harper and Row, 1964.

FAYOL, H. Administração industrial e geral: previsão, organização, comando, coordenação e controle. 10. Ed. São Paulo: Atlas, 1989.

FINKELMAN, J. (Org). Caminhos da saúde no Brasil. Rio de Janeiro: Editora Fiocruz, 2002. Disponível em: <http://books.scielo.org>. Acesso em: 27 dez. 2015.

FUNCIA, F. Implicações da Emenda Constitucional no 86/2015 para o processo de financiamento do Sistema Único de Saúde. Consensus - Revista do Conselho Nacional de Secretários de Saúde, ano V, n. 15, abr-jun 2015.

PIOLA, S. F. et al. Financiamento público da saúde: uma história à procura de rumo., Rio de Janeiro: Ipea, ju. 2013 (Texto para Discussão, 1.846).

ORTEGON, E.; PACHECO, J-F.; PRIETO, A. Metodologia del marco lógico para la planificación, el seguimiento y la evalución de proyectos y programas. Instituto Latinoamericano y del Caribe de Planificación Económica y Social (ILPES). Comisión Económica para América Latina y el Caribe (CEPAL). Santiago de Chile, jul. 2005 (Serie Manuales n. 42).

PAULO, L. F. A. O PPA como instrumento de planejamento e gestão estratégica. Revista do Serviço Público, Brasília, v. 61, n. 2, 2010, p. 171-187.

. Comentários sobre o PPA 2012-2015: gestão para resultados ou painel de políticas?

Revista Brasileira de Planejamento e Orçamento, v. 3, p. 44-64, 2013.

SANTOS, N. R. dos. Desenvolvimento do SUS, rumos estratégicos e estratégias para visualização dos rumos. Revista Ciência \& Saúde Coletiva. Rio de Janeiro, v. 12, n. 2, p. 429-435, 2007.

SERRA, A. Modelo Abierto de Gestión para Resultados en el Sector Público. Banco Interamericano de Desarrollo (BID). Centro Latinoamericano de Administración para el Desarrollo (CLAD). Santiago, jul. 2007.

SILVEIRA, J. P.; GARCES, A. Gestão pública orientada para resultados no Brasil. Revista do Serviço Público. Brasília, v. 53, n. 4, out-dez. 2002.

UNITED NATIONS DEVELOPMENT GROUP. Results-based managment handbook: strengthening RBM harmonization for improved development results. New York: UNO, 2010.

\section{Notas}

${ }^{1}$ A participação da União no financiamento da saúde caiu de 63,0\% em 1998, para 44,7\% em 2011. Para saber mais, ver Piola et al. (2013, p. 14) e Finkelman (2002, p. 276). 
${ }^{2}$ A expressão "Managing for Results" foi utilizada pela primeira vez por Peter Drucker, em livro lançado em 1964. Para saber mais sobre o surgimento da Gestão por Resultados, suas diversas denominações e a evolução no setor público, ver Serra (2007), UNDG (2010) e Bester (2012).

${ }^{3}$ Segundo Bester (2012, p. 8): “Gestão por Resultados como uma determinada prática ou abordagem ganhou importância nos anos 1990 como parte da agenda de reforma do setor público (também conhecida como Nova Gestão Pública) em alguns países da OCDE, como o Canadá. Agências bilaterias e multilaterais (Banco Mundial, por exemplo) passaram a adotar essa abordagem para a gestão de acordos de cooperação".

${ }^{4} \mathrm{O}$ planejamento estratégico é responsável por traçar os objetivos, ou resultados desejados, da organização, considerando cenários e o ambiente, enquanto a gestão por resultados consiste em uma estratégia para que a organização molde sua estrutura e os seus processos tendo como referência aqueles resultados definidos no planejamento. Para saber mais, ver Alday (2000), Silveira e Garces (2002), Barbosa e Brondani (2005) e Correa (2007).

${ }^{5}$ Ver esclarecimentos na seção seguinte.

${ }^{6} \mathrm{O}$ presente trabalho propõe um recorte essencialmente normativo. Para saber mais sobre a evolução do SUS e desafios para sua efetiva implementação, ver Carvalho (2001), Finkelman (2002), Santos (2007) e Carvalho e Santos (2013).

${ }^{7}$ A Lei no 8.080/90, em seu art. $3^{\circ}$, reconhece como determinantes e condicionantes de saúde, entre outros: alimentação, moradia, saneamento básico, meio ambiente, trabalho, renda, educação, atividade física, transporte, lazer e acesso aos bens e serviços essenciais.

${ }^{8}$ A descentralização é tratada como diretriz pela Constituição Federal de 1988 (art. 198, I) e como princípio pela Lei no 8.080/90 (art. 7º, IX). Para um contraponto ao movimento de descentralização das políticas públicas, ver Arretche (1996).

${ }^{9}$ Sobre os impactos da Emenda Constitucional no 86 sobre o financiamento da Saúde, ver Funcia (2015).

${ }^{10}$ É preciso destacar que o Ministério da Saúde realiza despesas que não são computadas como ações e serviços de saúde e, portanto, não computadas para apuração da aplicação do mínimo constitucional, nos termos previstos nos arts. $2^{\circ}$ a $4^{\circ}$ da Lei Complementar $n^{\circ} 141$.

${ }^{11}$ Essa regra não foi observada no PNS 2012-2015 porque o plano entrou em vigência antes da Lei Complementar $n^{\circ} 141$.

${ }^{12}$ Sobre o descumprimento reiterado do art. 35 da Lei no 8.080/90, ver Carvalho (2001, p. 437-ss).

${ }^{13}$ Considerando dados extraídos do Sistema Integrado de Planejamento e Orçamento (SIOP) referentes aos valores liquidados pelo Ministério da Saúde (MS) em outras despesas correntes e investimentos (GNDs 3 e 4) nas modalidades de aplicação referentes às transferências fundo a fundo em relação ao valores totais liquidados pelo MS nos GNDs 3 e 4 .

${ }^{14}$ Com base na variação do IPCA-geral entre dezembro de 2011 e dezembro de 2014.

${ }^{15}$ Considerando as transferências para o estado e para os municípios.

${ }^{16} \mathrm{O}$ Distrito Federal não foi considerado em razão de peculiaridades no financiamento dos serviços de saúde, que conta com participação direta da União.

${ }^{17} \mathrm{O}$ plano estratégico de cada país-membro, de vigência plurianual, recebe o nome de Marco de Assistência das Nações Unidas para o Desenvolvimento, em inglês UNDAF - United Nations Development Assistence Framework.

${ }^{18}$ PNS ou PPA. 
${ }^{19}$ Entre os 14 princípios da Teoria Clássica da Administração, inaugurada por Henry Fayol, ao menos três estão diretamente relacionados à unidade de comando nas organizações (unidade de comando, unidade de direção e centralização). Para saber mais, ver Chiavenato (2006, p. 13) e Fayol (1989).

${ }^{20}$ Para saber mais sobre o modelo do PPA, ver Paulo (2010 e 2013).

${ }^{21}$ Conforme definido na seção 1 , tendo como referência o conceito empregado pela ONU, resultado como alteraçóes desejadas na realidade. Na forma de pergunta orientadora, resultado no plano estratégico deve responder ao questionamento "do que se quer", que não deve ser confundido com "o que fazer", que revela a estratégia adotada para atingir o resultado pretendido. 
Strategic Planning and result-based

management: a study on the Brazilian

Ministry of Health

This study aimed to evaluate to what extent the strategic planning of the Ministry of Health (MOH) is bonded to a results-based management strategy, focusing particularly on strategic choices that guide the organization, namely the pursued results. The first section explains the methodological assumptions used in the study, which is guided by three key aspects: 1) the legal powers of the Federal Government in health care; 2) concepts and definitions about Result-Based Management (RBM); and 3) the definition of outcome to the strategic plan. The second section briefly presents how the strategic planning of Ministry of Health is formalized through three strategic plans simultaneously (Plano Plurianual, Plano Nacional de Saúde and Plano Estratégico) to then assess whether this planning is adherent to the methodological assumptions presented in the first section. It concludes that the strategic planning for the health sector does not observe the division of powers defined by the Brazilian Constitution and legislation, establishing goals that considerably exceed the governance sphere of the Federal Government. This same design also elects as goals administrative measures of operational nature, which should not be presented in strategic plans.

> Key words: Result-Based Management; strategic planning; public management; Brazilian Health System. 